\title{
The Carnegie Institution of Washington, Department of Embryology
}

\author{
Allan C. Spradling, Ph.D., Director
}

Since its founding in 1902, the Carnegie Institution of Washington has made many prominent contributions to the nation's scientific development. In establishing one of the first organizations devoted exclusively to scientific research, Andrew Carnegie envisioned an evolving engine for discovery that would focus at any given time on areas offering unusual opportunities to advance basic knowledge. During the last 95 years autonomous Carnegie departments have probed diverse subjects ranging from nutrition, marine biology, and genetics to archaeology, astrometry, and economics. Currently the Institution consists of five departments: the Carnegie Observatories, the Geophysical Laboratory, and the Departments of Embryology, Plant Biology, and Terrestrial Magnetism (earth sciences and cosmology). The Department of Embryology, located in Baltimore and affiliated with the Johns Hopkins University, is the primary locus of research in the medical sciences.

Research in the Department of Embryology has evolved continuously since its founding in 1913. After largely accomplishing its original mission to describe human embryonic development the department turned toward questions of primate reproductive physiology. Later, during the tenure of the two most recent previous directors, James Ebert and Donald Brown, a critical mass of scientists interested in understanding embryonic development in molecular terms was assembled and began to flourish. Today work in the department utilizes yeast, planaria, worms, flies, fish, frogs, and mice to address a wide range

Address correspondence and reprint requests to: Dr. Allan C. Spradling, Carnegie Institution of Washington, 1530 P Street Northwest, Washington, D.C. 20005-1910, U.S.A. Tel: 202-387-6400; Fax: 202-387-8092; e-mail: spradling@maill.ciwemb.edu

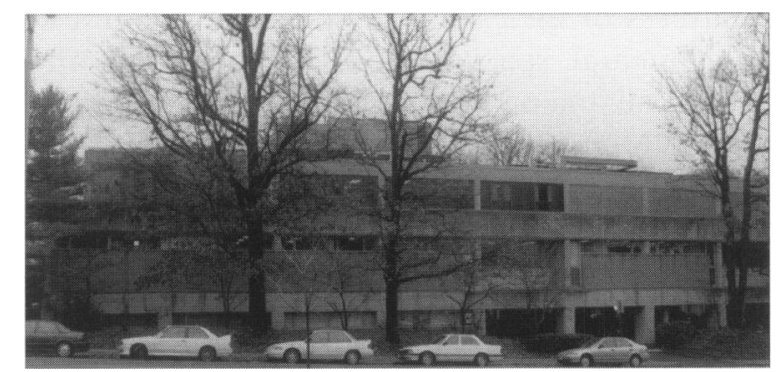

of issues in cell and developmental biology. Particular emphasis at present lies in two areas: 1) the structure and function of chromosomes and 2 ) the role of intercellular signaling in vertebrate embryos.

\section{DEPARTMENTAL PHILOSOPHY}

Scientific leadership requires exceptional individuals with the insight, resources, and courage to investigate the margins of what is feasible and respectable. The department makes every effort to hire the most creative and skilled researchers while paying relatively little attention to their area of current interest. It is recognized that the working environment profoundly influences the research directions chosen even by highly talented individuals. Bold ventures are encouraged by providing stimulating intellectual and material resources. Faculty interests are expected to evolve in directions that lead rather than follow change. Despite the recent development of large scale biological resources such as genome projects, the department believes strongly that investigator-initiated research within small groups of highly talented colleagues remains the most potent known engine for discovery. 
Several features of the research environment at Embryology are designed to bolster scientific creativity. There is no tenure system. Instead, all faculty are evaluated at five-year intervals. Emphasis is placed on the originality and long-term significance of a research program, rather than professional visibility. Communication is fostered in several ways. A steady flow of new associates, postdoctoral fellows, students, and visitors is encouraged. Research groups must remain relatively small (less than ten) to facilitate communication between faculty and lab members and to make it easier for faculty to remain experimentally engaged. All regular faculty have the same amount of personal laboratory space, regardless of their seniority or group size. Most departmental space remains in common and houses all major equipment items, which are shared. Members of different groups frequently reside in the common labs, where they work side by side. Many supplies are also purchased collectively and distributed from open stock rooms. All scientists present a department-wide progress report once or twice a year, in addition to participating in regular group meetings. These meetings routinely generate numerous questions and extended discussion. Thus, scientists at Embryology become participants in an intellectual tradition that transcends simple membership in a particular research lab.

\section{FACULTY AND FACILITIES}

There are eight regular faculty who maintain independent, autonomous research groups as in a university department. Faculty size has remained unchanged since the department was founded, because it is felt that further increases would diminish the mutual interactions that we prize. However, the department does not feel "small." The Embryology building is located on the main campus of the Johns Hopkins University, and staff members hold appointments as adjunct faculty in the Department of Biology. Interactions with Biology faculty and graduate students greatly expand the department's horizons. Currently, two faculty members are Investigators of the Howard Hughes Medical Institute (HHMI), providing additional regular contacts with a diverse group of talented researchers. Finally, the department hosts seminars by many leading scientists, who, like insects in the night, are drawn to the Baltimore-Washington area on a regular basis.

Undoubtedly the department's breadth has been expanded most by its staff associate program. Staff associates are independent junior faculty members who hold non-renewable facultylevel appointments for up to five years. They may be appointed in lieu of or after completing a regular postdoctoral fellowship. Staff associates work at the bench, sometimes with the help of a technician or summer student. It is a time for these young scientists to build a research program with no distractions. While pursuing independent goals, staff associates remain closely connected to the department through the natural interactions described above. Thanks in part to the generosity of the Keck Foundation, new laboratories are now available for each staff associate.

With regularity staff associates question accepted wisdom, venture in new directions, and pursue unproved, risk-prone projects long enough for hidden merits to be revealed. Maintaining a venue for promising but risky ventures has become especially important as our national research system increasingly selects for projects that propose to extend accepted wisdom, not to challenge it. This slide toward a short-term, goaldriven research enterprise dominated by senior scientists, long the norm in most countries, is the simple, conservative, but mistaken, way to support research. Because our program has succeeded in nurturing many outstanding scientists, the number of staff associate positions has been increased to four in recent years.

The department's traditional closeness also helps it to provide outstanding research support. A new transgenic mouse facility, part of the department's Keck Foundation Laboratory for Vertebrate Development, is available to all groups. Mouse costs are partially subsidized by the department. An HHMI-supported biotechnology center synthesizes oligonucleotides and carries out automated DNA sequencing. The department maintains an extensive computer network, with advanced graphic and slidemaking capabilities. Institute personnel also provide secretarial, photographic, software, and machine shop services. Other personnel wash glassware and prepare culture media.

\section{EDUCATIONAL GOALS}

The department strives to excel in graduate and postgraduate training as well as research. Each graduate student and postdoctoral fellow is expected to pursue a distinct and scientifically com- 
plete research project. While sharing facilities, equipment, and ideas, each researcher participates fully in the design, execution, and interpretation of his or her experiments. The interactive environment within the department, including frequent seminars, journal clubs, and progress reports, stimulates the intellectual development of young scientists. Each year two graduate students or postdocs organize a "Carnegie Minisymposium" during which they serve as hosts to five leading scientists in an area of current interest to the department. The Institute also provides funding for each trainee to attend at least one major scientific meeting (such as a Gordon Conference) per year.

\section{CONCLUSION}

New insights ultimately depend on opportunities available to individual scientists. The philosophy and resources available within the Department of Embryology should continue to engender exceptional scientific creativity and accomplishment in the years to come. 